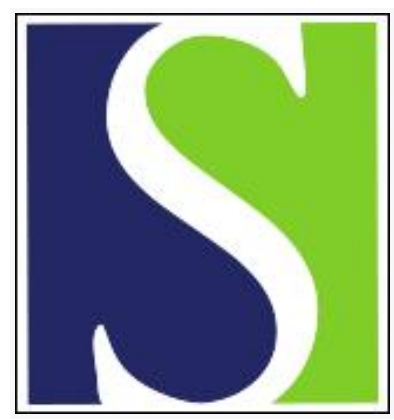

Scand J Work Environ Health 2014;40(3):235-243

https://doi.org/10.5271/sjweh.3408

Published online: 05 Dec 2013, Issue date: 01 May 2014

Associations of traffic noise with self-rated health and psychotropic medication use

by Halonen JI, Lanki T, Yli-Tuomi T, Turunen AW, Pentti J, Kivimäki M, Vahtera J

This study shows that road traffic noise $>60 \mathrm{~dB}$ (compared to $<45 \mathrm{~dB}$ ) was associated with poor self-rated health in men, but not in women. This association was stronger among men with high trait anxiety scores. Noise levels were not associated with psychotropic medication use.

Affiliation: Finnish Institute of Occupational Health, PO Box 310, 70101 Kuopio, Finland. jaana.halonen@ttl.fi

Refers to the following text of the Journal: 2006;32(5):392-401

The following article refers to this text: 2014;40(3):211-213

Key terms: antidepressant; anxiety; cohort study; environmental noise; noise; psychotropic medication; road traffic; self-rated health; traffic noise; trait anxiety; vulnerable

This article in PubMed: www.ncbi.nlm.nih.gov/pubmed/24788851

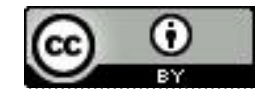




\title{
Associations of traffic noise with self-rated health and psychotropic medication use
}

\author{
by Jaana I Halonen, PhD, ${ }^{1}$ Timo Lanki, PhD, ${ }^{2}$ Tarja Yli-Tuomi, PhD, ${ }^{2}$ Anu W Turunen, PhD, ${ }^{2}$ Jaana Pentti, \\ MSc, ${ }^{1}$ Mika Kivimäki, PhD, ${ }^{1,3}$ Jussi Vahtera, MD ${ }^{1,4}$
}

\begin{abstract}
Halonen JI, Lanki T, Yli-Tuomi T, Turunen AW, Pentti J, Kivimäki M, Vahtera J. Associations of traffic noise with self-rated health and psychotropic medication use. Scand J Work Environ Health. 2014;40(3):235-243. doi:10.5271/sjweh.3408
\end{abstract}

Objectives Road traffic noise is a common environmental nuisance, which has been thought to increase the risk of many types of health problems. However, population-level evidence often remains scarce. This study examined whether road traffic noise is associated with self-rated health and use of psychotropic medication in a cohort of public sector employees.

Methods Data are from the Finnish Public Sector Study cohort. Geographical information system (GIS) was used to link modeled outdoor road traffic noise levels $\left(\mathrm{L}_{\text {den }}\right)$ to residential addresses of 15611 men and women with cross-sectional survey responses on self-rated health and register-based information on the use of antidepressants, anxiolytics, and hypnotics. High trait anxiety scores were used to identify potentially vulnerable individuals. The analyses were run with logistic regression models adjusting for individual and area-level variables. All participants were blind to the aim of the study.

Results Mean level of road traffic noise at participants' home addresses was 52 decibels (dB) (standard deviation 8.1). Noise level $>60 \mathrm{~dB}$ versus $\leq 45 \mathrm{~dB}$ was associated with poor self-rated health in men [odds ratio (OR) $1.58,95 \%$ confidence interval $(95 \%$ CI) $1.14-2.21$ ]. Further stratification revealed that the association was evident only among men with high trait anxiety scores (OR 2.23, 95\% CI 1.28-3.89). No association was found with psychotropic medication use or among women.

Conclusion Exposure to road traffic noise was not associated with increased use of psychotropic medication, although it was associated with weakened self-rated health among men.

Key terms antidepressant; anxiety; cohort study; environmental noise; road traffic; trait anxiety; vulnerable.

With ever increasing traffic volumes and urbanization, road traffic noise is already one of the most common environmental nuisances globally. The World Health Organization (WHO) recommends noise levels of $<50$ decibels $(\mathrm{dB})$ and $<40 \mathrm{~dB}$ at day- and night-time, respectively, to limit public disturbance $(1,2)$. More recently, to identify populations exposed to high noise levels, the European Commission required environmental noise maps for urban areas with populations of $>100000$ persons and roads with $>3$ million vehicles per year (3). Based on these noise maps and other estimates, even in scarcely populated Finland, nearly one fifth of the population is exposed to road traffic noise levels $>55 \mathrm{~dB}$ (4).
The WHO has estimated that more than a million healthy life years are lost due to traffic noise in Western Europe (5). Epidemiological studies have reported associations between road traffic noise and cardiovascular health, but the possible confounding by air pollution from traffic has often not been taken into account (6). Associations have been reported also between noise and eg, sleep problems (7-9), annoyance $(10,11)$ and decreased health-related quality of life (12). Further evidence suggests that aircraft noise is associated with poor self-rated health and generalized anxiety disorder $(13,14)$, and decreased children's cognitive performance $(15,16)$. However, only a few studies have looked at

1 Finnish Institute of Occupational Health, Kuopio/ Turku/ Helsinki, Finland.

2 Department of Environmental Health, National Institute for Health and Welfare, Kuopio, Finland.

3 Department of Epidemiology and Public Health, University College of London, London, UK

4 Department of Public Health, University of Turku and Turku University Hospital, Finland.

Correspondence to: Jaana I Halonen, Finnish Institute of Occupational Health, PO Box 310, 70101 Kuopio, Finland. [E-mail: jaana.halonen@ ttl.fi] 
associations between road traffic noise (a more common environmental nuisance than aircraft noise) and self-rated health (8) or psychotropic medication use (eg, hypnotics) (17-19) among adults, and even fewer have studied how noise-sensitivity affects these associations (20).

In this study, we examined whether traffic noise is associated with self-rated health and register-based psychotropic medication use. More than 15600 men and women participated in the study and were blind to its aim. We also stratified the analyses by trait anxiety as the associations may be stronger in population groups sensitive to noise (7).

\section{Methods}

\section{Study population}

Participants of the Finnish Public Sector Study, an on-going prospective study among employees of ten towns and six hospital districts, provided the basis for the study population. The sex and age distribution of the whole cohort is representative of Finnish public sector employees $(75 \%$ women in this cohort versus $77 \%$ women in the public sector; mean age of all participants 44 versus 45 years, respectively), and the participants cover a wide range of occupational groups. Surveys were mailed to all current employees at the participating organizations in 2000, 2004 and 2008, as well as in 2005 and 2009 for those participants who completed questionnaires while employed, but thereafter had left the participating organization (response rate $69 \%$ ). Coordinate data of the participants' residential addresses and the dates of moves (at the level of street name and number) between 2000 and 2010 were obtained from the Population Register Center and the address at the time of the survey was used for the modeling. The modeled traffic noise levels were available for the cities of Turku, Helsinki and Vantaa, and thus cohort participants living in these cities were included in this study. The final sample was 15611 men and women. The ethics committee of the Hospital District of Helsinki and Uusimaa has approved the Finnish Public Sector study, including this work.

\section{Assessment of road traffic noise levels}

For each participant, we used data from the study year that was chronologically the closest to the noise modeling period (ie, 2011 in Turku, 2006 in Helsinki, and 2005 in Vantaa). Because of the variation in the modeling periods, the modeling was done before the survey for some participants and after for others. The difference between the survey and noise modeling years was on average 3.2 years. The exposure variable was road traffic noise level $\left(\mathrm{L}_{\mathrm{den}}\right)$, which is the average value of the annual noise level with weighting factors of $5 \mathrm{~dB}(\mathrm{~A})$ for the four-hour evening period, and $10 \mathrm{~dB}(\mathrm{~A})$ for the eight-hour night period. Noise levels in the cities of Turku (21), Helsinki (22) and Vantaa (23) were modeled for major highways and the main and collector streets using the Nordic prediction methods (24), $10 \mathrm{~m}$ grid size, and calculation height of $4 \mathrm{~m}$. Temporal variation of traffic intensity was automatically measured by a traffic monitoring system at several main and collector streets in all three cities. Smaller streets that had no data on traffic intensity were excluded from the noise model. First order reflection and the effect of noise barriers were included in the noise calculations. Data resolution was $0.1 \mathrm{~dB}$.

We linked the modeled noise levels to the survey data using the coordinates of the exposure points and the residential addresses of participants. Noise levels at the most exposed façades of residential buildings were estimated using ArcMap 10 (Esri, Redlands, CA, USA). First, we removed all noise grid points on top of buildings. Then, two closest noise grid points within a $20 \mathrm{~m}$ buffer around the residence coordinates were identified for each residence and the higher of these points was selected to represent the noise exposure. For the analyses, we categorized traffic noise into five classes: $\leq 45$ (reference, number of participants $=2821$ ), $45.1-50$ $(\mathrm{N}=4110), 50.1-55(\mathrm{~N}=3597), 55.1-60(\mathrm{~N}=2445)$, and $>60 \mathrm{~dB}(\mathrm{~N}=2638)(7)$.

\section{Assessment of outcome variables}

The respondents assessed their health status on a 5-point scale $(1=$ very good, $2=$ good, $3=$ average, $4=$ poor, $5=$ very poor). This measure was dichotomized and used as an indicator of poor self-rated health (average/poor/very poor versus good/very good). This is one of the most widely used measures of health status (25), shown to be related to a number of important medical endpoints and sensitive to changes in health status $(26,27)$.

For psychotropic medication use, individual-level information on the dates of filled outpatient prescriptions was obtained from the National Prescription Register, managed by the Social Insurance Institution of Finland (28). The national sickness insurance scheme covers the entire population, regardless of age or occupational title, and provides reimbursement for all filled prescriptions. Based on the WHO Anatomical Therapeutic Chemical (ATC) classification codes (29), we chose anxiolytics (N05B), hypnotics (N05C), and antidepressants (N06A) to determine a summary variable for psychotropic medication use (yes versus no) during the year of the survey, as in a prior study (30). 


\section{Assessment of trait anxiety}

Anxious people are vigilant to the potentially threatening aspects of the environment (31) and may therefore be particularly sensitive to noise. As in our prior study (7), we used a trait anxiety score as an indicator of noise sensitivity. The score was derived from a 6 -item trait anxiety inventory (a short version of the 20 -item Spielberger trait anxiety inventory) (32) about how the person generally feels ("I feel calm", "I am relaxed", "I feel satisfied", I feel tense", "I feel upset", "I am worried"; all items are rated on a 4-point scale: "not at all=1", "a little=2", "to some degree=3", "very much so $=4$ "). When responses to $\geq 4$ of the 6 questions were available, we calculated the mean value of these points to get the trait anxiety score (reverse scaling used for "I feel calm", "I am relaxed", and "I feel satisfied"). Values higher than mean indicated "high trait anxiety score".

\section{Individual-level covariates}

Age, sex, and socioeconomic status (SES) can be significant confounders of the association between traffic noise and health (8). We obtained information on age, sex, and occupational titles of the participants from the employers' registers. Occupational status was used as an indicator of individual SES and categorized into three groups (high=upper grade non-manual workers, intermediate=lower grade non-manual workers, and low=manual workers) based on Statistics Finland's Classification of Occupations (33). Other proxies for individual SES were the level of education (high=university degree, intermediate=high school or vocational school, low $=$ comprehensive school) obtained from Statistics Finland, and size of apartment (high $>100$, intermediate $=$ $70-100$, low $<70 \mathrm{~m}^{2}$ ) from the Population Register Center.

Information on other possible confounders, such as work stress and lifestyle factors, was obtained from the surveys: job strain [high demand and low control (34)], smoking status (current smoker versus non-smoker), leisure-time physical inactivity $[<2$ metabolic equivalent task hours per day, ie, approximately 30 minutes brisk walking per day (35)], obesity [body mass index (BMI) $\geq 30$ versus $\left.<30 \mathrm{~kg} / \mathrm{m}^{2}\right]$, and heavy alcohol consumption [ $\geq 24$ drinks/week for men, $\geq 16$ drinks/week for women (36)].

We also collected data on chronic somatic illnesses from the Drug Reimbursement Register of the Social Insurance Institution of Finland (37) to build a "chronic disease" indicator (yes versus no). The register contains individual-level information on entitlements to special reimbursement for the cost of medication for chronic illnesses (hypertension, cardiac failure, ischemic heart disease, diabetes, asthma or other chronic obstructive lung disease, rheumatoid arthritis, and severe mental dis- orders), and the date of reimbursement. Data on cancer diagnoses, obtained from the Finnish Cancer Registry, was also used to build the indicator (38).

\section{Area-level covariates}

Because both traffic noise levels and health status have been found to vary by area-level SES $(39,40)$, we obtained area-level socioeconomic variables from the grid database of Statistics Finland (41). An index for area-level socioeconomic disadvantage was calculated for each $250 \times 250 \mathrm{~m}$ map grid ("a neighborhood") using information on the median household income, level of education, and unemployment rate (42). As a proxy for the degree of urbanization in the neighborhood, we used population density that was calculated by dividing the total number of residents within each map grid by the surface area of the map grid (inhabitants $/ \mathrm{km}^{2}$ ).

\section{Statistical analysis}

Logistic regression models for the categorized exposure (GENMOD procedure of SAS 9.3, SAS Institute, Cary, NC, USA) were used to study associations between noise and the dichotomized outcome variables as well as possible trends and curvilinearity in these associations. All analyses were stratified by sex because the association may vary by sex and also because the analytical sample was female dominated ( $80 \%$ women). Models were first run without adjustments (Model 1) and then adjusted for age, marital status, individual-level SES variables, job strain, chronic disease, area-level SES, and population density (Model 2). Those participants with missing data were excluded from the analyses. The models were then stratified by trait anxiety to examine whether associations were different among those likely to be more sensitive to noise.

In further analyses, we adjusted the models for the following lifestyle risk factors: smoking, heavy alcohol use, physical inactivity, and obesity. A separate analysis was run using noise categorization: $\leq 45,45.1-50,50.1-$ $55,55.1-60,60.1-65$, and $>65 \mathrm{~dB}$, although the number of those exposed to the highest noise level $(>65 \mathrm{~dB})$ was low (men=267, women=949). We also ran the models including only those who had lived in the address of the survey date for $\geq 3$ years $(\mathrm{N}=12$ 336) and models for the medication use by individual medications.

\section{Results}

The mean age of the 15611 study participants was 50.3 (range 21-76) years. The mean noise level at the residential address was $52 \mathrm{~dB}$ (standard deviation 8.1, 
range $18-79 \mathrm{~dB})$. Of the participants, 4417 (28.3\%) had poor self-rated health and $2573(16.5 \%)$ had purchased any psychotropic medication [1617 (10.4\%), antidepressants, $592(3.8 \%)$ anxiolytics, and $1152(7.4 \%)$ hypnotics]. Detailed description of the study population by sex and categorized noise levels is provided in tables 1 and 2.

After adjustment for age, occupational status, level of education, size of residence, marital status, job strain, chronic disease, area-level socioeconomic status and population density, a statistically significant association was observed between noise $>60$ (versus $\leq 45) \mathrm{dB}$ and poor self-rated health among men (table $3)$. There was also evidence of linear trend for this association (test for trend $\mathrm{P}<0.01$ ), and no evidence of curvilinearity (test for trend $\mathrm{P}>0.05$ ). No associations were observed for psychotropic medication use (table 3). Among women, no significant associations were observed in the adjusted models for either of the outcomes (table 4).

In the analyses stratified by noise sensitivity as indicated by trait anxiety score, the association between noise at the highest level and poor self-rated health among men was more pronounced among those reporting a high anxiety score in Model 2 (table 5). The stratification did not reveal associations for traffic noise and psychotropic medication use among men or for traffic noise and the two outcomes among women (data not shown).

Further adjustment for smoking, heavy alcohol use, physical inactivity and obesity had little effect on the association found for men (OR 1.51, 95\% CI 1.06-2.16 for $>60$ versus $\leq 45 \mathrm{~dB}$ ); no associations were observed for women (data not shown). Although the number of those exposed to the higher noise levels $(60-65$ and $>65 \mathrm{~dB})$ was low, exposure to $60-65$ versus $\leq 45 \mathrm{~dB}$ (OR $1.52,95 \%$ CI 1.02-2.27) and exposure to $>65$ versus $\leq 45 \mathrm{~dB}$ (OR $1.66,95 \%$ CI 1.10-2.49) were associated with poor selfrated health among men but not women. In the analyses restricted to those who had resided in the same address $\geq 3$ years, the association in the highest noise category $(>60$ $\mathrm{dB}$ ) was strengthened with the adjusted OR being 1.90 (95\% CI 1.30-2.78) among all men. For individual medications, no associations were observed (data not shown).

Table 1. Descriptive statistics of the participating men by road traffic noise levels.

\begin{tabular}{|c|c|c|c|c|c|c|c|c|c|c|c|c|}
\hline \multirow[t]{3}{*}{ Individual covariates } & \multirow[t]{3}{*}{$\mathrm{N}$} & \multirow[t]{3}{*}{$\%$} & \multicolumn{10}{|c|}{ Road traffic noise, dB $\left(L_{\text {den }}\right)$} \\
\hline & & & \multicolumn{2}{|c|}{$\leq 45$} & \multicolumn{2}{|c|}{$45.1-50$} & \multicolumn{2}{|c|}{$50.1-55$} & \multicolumn{2}{|c|}{$55.1-60$} & \multicolumn{2}{|c|}{$>60$} \\
\hline & & & $\mathrm{N}$ & $\%$ & $\mathrm{~N}$ & $\%$ & $\mathrm{~N}$ & $\%$ & $\mathrm{~N}$ & $\%$ & $\mathrm{~N}$ & $\%$ \\
\hline Married/cohabiting & 3050 & & & & & & & & & & & \\
\hline No & 734 & 24.0 & 137 & 25.5 & 166 & 20.2 & 163 & 23.0 & 107 & 23.6 & 161 & 30.5 \\
\hline Occupational status & 3041 & & & & & & & & & & & \\
\hline High & 1448 & 47.6 & 265 & 49.1 & 410 & 50.3 & 321 & 45.6 & 203 & 44.5 & 249 & 47.3 \\
\hline Intermediate & 723 & 23.8 & 133 & 24.6 & 186 & 22.8 & 169 & 24.0 & 107 & 23.5 & 128 & 24.3 \\
\hline Low & 870 & 28.6 & 142 & 26.3 & 219 & 26.9 & 214 & 30.4 & 146 & 32.0 & 149 & 28.3 \\
\hline Residence size & 3062 & & & & & & & & & & & \\
\hline Large $\left(>100 \mathrm{~m}^{2}\right)$ & 875 & 28.6 & 155 & 28.4 & 265 & 32.4 & 217 & 30.5 & 126 & 27.7 & 112 & 21.1 \\
\hline Intermediate $\left(70-100 \mathrm{~m}^{2}\right)$ & 1155 & 37.7 & 200 & 36.6 & 323 & 39.5 & 265 & 37.2 & 172 & 37.8 & 195 & 36.7 \\
\hline Small $\left(<70 \mathrm{~m}^{2}\right)$ & 1032 & 33.7 & 191 & 35.0 & 230 & 28.1 & 230 & 32.3 & 157 & 34.5 & 224 & 42.2 \\
\hline Education & 3086 & & & & & & & & & & & \\
\hline High & 1772 & 57.4 & 325 & 59.2 & 492 & 59.6 & 394 & 55.0 & 252 & 54.7 & 309 & 57.9 \\
\hline Intermediate & 896 & 29.0 & 153 & 27.9 & 222 & 26.9 & 222 & 31.0 & 139 & 30.2 & 160 & 30.0 \\
\hline Low & 418 & 13.5 & 71 & 12.9 & 112 & 13.6 & 100 & 14.0 & 70 & 15.2 & 65 & 12.2 \\
\hline Job strain & 2344 & & & & & & & & & & & \\
\hline Yes & 415 & 17.7 & 74 & 17.5 & 112 & 17.7 & 89 & 16.6 & 66 & 19.0 & 74 & 18.1 \\
\hline Trait anxiety & 3002 & & & & & & & & & & & \\
\hline High & 989 & 32.9 & 173 & 32.4 & 275 & 34.0 & 224 & 31.9 & 148 & 33.4 & 169 & 32.9 \\
\hline Chronic disease & 3086 & & & & & & & & & & & \\
\hline Yes & 618 & 20.0 & 117 & 21.3 & 158 & 19.1 & 144 & 20.1 & 98 & 21.3 & 101 & 18.9 \\
\hline Obese & 3034 & & & & & & & & & & & \\
\hline Yes & 500 & 16.5 & 81 & 15.0 & 129 & 16.0 & 124 & 17.5 & 71 & 15.6 & 95 & 18.1 \\
\hline Current smoker & 3042 & & & & & & & & & & & \\
\hline Yes & 582 & 19.1 & 95 & 17.6 & 149 & 18.2 & 146 & 20.7 & 87 & 19.1 & 105 & 20.1 \\
\hline Physically inactive & 3053 & & & & & & & & & & & \\
\hline Yes & 856 & 28.0 & 154 & 28.5 & 221 & 27.0 & 208 & 29.5 & 124 & 27.1 & 149 & 28.2 \\
\hline Heavy alcohol user & 3058 & & & & & & & & & & & \\
\hline Yes & 386 & 12.6 & 64 & 11.7 & 106 & 12.9 & 84 & 11.9 & 61 & 13.4 & 71 & 13.5 \\
\hline Outcome & & & & & & & & & & & & \\
\hline Poor self-rated health & 3069 & & & & & & & & & & & \\
\hline Yes & 887 & 28.9 & 145 & 26.6 & 209 & 25.5 & 217 & 30.6 & 137 & 29.7 & 179 & 33.7 \\
\hline Psychotropic medication use & 3086 & & & & & & & & & & & \\
\hline Yes & 381 & 12.3 & 73 & 13.3 & 92 & 11.1 & 99 & 13.8 & 51 & 11.1 & 66 & 12.4 \\
\hline
\end{tabular}


Table 2. Descriptive statistics of the participating women by road traffic noise levels.

\begin{tabular}{|c|c|c|c|c|c|c|c|c|c|c|c|c|}
\hline \multirow[t]{3}{*}{ Individual covariates } & \multirow[t]{3}{*}{$\mathrm{N}$} & \multirow[t]{3}{*}{$\%$} & \multicolumn{10}{|c|}{ Road traffic noise, $\mathrm{dB}\left(\mathrm{L}_{\text {den }}\right)$} \\
\hline & & & \multicolumn{2}{|c|}{$\leq 45$} & \multicolumn{2}{|c|}{$45.1-50$} & \multicolumn{2}{|c|}{$50.1-55$} & \multicolumn{2}{|c|}{$55.1-60$} & \multicolumn{2}{|c|}{$>60$} \\
\hline & & & $\mathrm{N}$ & $\%$ & $\mathrm{~N}$ & $\%$ & $\mathrm{~N}$ & $\%$ & $\mathrm{~N}$ & $\%$ & $\mathrm{~N}$ & $\%$ \\
\hline Married/cohabiting & 12366 & & & & & & & & & & & \\
\hline No & 3992 & 32.3 & 794 & 35.3 & 955 & 29.3 & 859 & 30.2 & 604 & 30.9 & 780 & 37.8 \\
\hline Occupational status & 12408 & & & & & & & & & & & \\
\hline High & 4186 & 33.7 & 761 & 33.6 & 1065 & 32.8 & 955 & 33.5 & 673 & 34.3 & 732 & 35.1 \\
\hline Intermediate & 6544 & 52.7 & 1148 & 50.7 & 1746 & 53.8 & 1564 & 54.9 & 1016 & 51.8 & 1070 & 51.3 \\
\hline Low & 1678 & 13.5 & 356 & 15.7 & 434 & 13.4 & 329 & 11.6 & 274 & 14.0 & 285 & 13.7 \\
\hline Residence size & 12459 & & & & & & & & & & & \\
\hline Large $\left(>100 \mathrm{~m}^{2}\right)$ & 3070 & 24.6 & 413 & 18.3 & 918 & 28.1 & 821 & 28.6 & 516 & 26.2 & 402 & 19.2 \\
\hline Intermediate $\left(70-100 \mathrm{~m}^{2}\right)$ & 4960 & 39.8 & 963 & 42.6 & 1326 & 40.6 & 1131 & 39.4 & 778 & 39.5 & 762 & 36.4 \\
\hline Small $\left(<70 \mathrm{~m}^{2}\right)$ & 4429 & 35.5 & 883 & 39.1 & 1024 & 31.3 & 919 & 32.0 & 676 & 34.3 & 927 & 44.3 \\
\hline Education & 12525 & 0.0.0 & 000 & (50.1 & $10<7$ & & & & & & & \\
\hline High & 6724 & 53.7 & 1223 & 53.8 & 1742 & 53.1 & 1538 & 53.4 & 1037 & 52.3 & 1184 & 56.3 \\
\hline Intermediate & 4356 & 34.8 & 812 & 35.7 & 1148 & 35.0 & 984 & 34.2 & 709 & 35.7 & 703 & 33.4 \\
\hline Low & 1445 & 11.5 & 237 & 10.4 & 394 & 12.0 & 359 & 12.5 & 238 & 12.0 & 217 & 10.3 \\
\hline Job strain & 9194 & & & & & & & & & & & \\
\hline Yes & 2285 & 24.9 & 437 & 26.4 & 601 & 24.5 & 529 & 25.1 & 360 & 24.8 & 358 & 23.4 \\
\hline Trait anxiety & 12195 & & & & & & & & & & & \\
\hline High & 4123 & 33.8 & 751 & 34.0 & 1088 & 34.0 & 964 & 34.4 & 637 & 33.0 & 683 & 33.4 \\
\hline Chronic disease & 12525 & & & & & & & & & & & \\
\hline Yes & 2117 & 16.9 & 366 & 16.1 & 544 & 16.6 & 519 & 18.0 & 356 & 17.9 & 332 & 15.8 \\
\hline Obese & 12136 & & & & & & & & & & & \\
\hline Yes & 1890 & 15.6 & 338 & 15.3 & 510 & 16.0 & 420 & 15.1 & 321 & 16.7 & 301 & 14.8 \\
\hline Current smoker & 12326 & 1.0 & & & & & & & & & & \\
\hline Yes & 1789 & 14.5 & 335 & 15.0 & 441 & 13.6 & 400 & 14.1 & 297 & 15.2 & 316 & 15.3 \\
\hline Physically inactive & 12395 & & & & & & & & & & & \\
\hline Yes & 3186 & 25.7 & 567 & 25.3 & 835 & 25.6 & 724 & 25.4 & 534 & 27.2 & 526 & 25.3 \\
\hline Heavy alcohol user & 12413 & & & & & & & & & & & \\
\hline $\begin{array}{l}\text { Yes } \\
\text { Outcome }\end{array}$ & 1242 & 10.0 & 247 & 11.0 & 307 & 9.4 & 269 & 9.4 & 182 & 9.3 & 237 & 11.4 \\
\hline Poor self-rated health & 12416 & & & & & & & & & & & \\
\hline Yes & 3530 & 28.4 & 680 & 30.2 & 936 & 28.7 & 800 & 28.0 & 552 & 28.0 & 562 & 27.1 \\
\hline Psychotropic medication use & 12525 & & & & & & & & & & & \\
\hline Yes & 2192 & 17.5 & 412 & 18.1 & 558 & 17.0 & 477 & 16.6 & 356 & 17.9 & 389 & 18.5 \\
\hline
\end{tabular}

\section{Discussion}

In this study, exposure to road traffic noise $>60$ compared with $\leq 45 \mathrm{~dB}$ was associated with an increased risk of poor self-rated health among men, particularly those with high trait anxiety, but not among women. We found no evidence to suggest that traffic noise would be associated with register-based use of psychotropic medication.

Our findings for men are in agreement with a recent study on Swiss people, which indicated that traffic noise is associated with self-reported health status, although they did not report sex-specific results (8), and with a study showing aircraft noise at $50 \mathrm{~dB}\left(\mathrm{~L}_{\mathrm{den}}\right)$ to be related to poor self-rated health among those living within 25 $\mathrm{km}$ of an airport (14). In one of the earlier works, acute health symptoms (eg, irritability and difficulty getting to sleep) were more commonly reported among those living in areas of aircraft noise levels of $\geq 45 \mathrm{~dB}$ compared to $<45 \mathrm{~dB}(43)$. Another study found associations between perceived street noise and physical and mental dimensions of health-related quality of life (12), but as the street noise was measured with self-reports the finding may be attributable to reporting bias or common methods bias, both artificially inflating associations. Chronic illnesses, lack of physical exercise, and psychological distress, for example, are shown to lead to weakened self-rated health $(44,45)$. Mechanisms of the effect of noise on self-rated health are not known, but in principle all these pathways may be relevant: traffic noise has been associated, for example, with chronic cardiovascular diseases, decreased willingness to go out walking, and increased stress reactions $(12,46,47)$.

The use of psychotropic medication, including anxiolytics, hypnotics, and antidepressants, was not associated with noise levels. These findings agree with the HYENA study reporting no association between traffic noise and use of anxiolytics (17), although in that study there was an association between aircraft noise exposure and use of anxiolytics. Two other studies have assessed associations between night-time traffic noise and sleep medication use but reported conflicting results $(18,19)$. In a subset of our cohort, we previously found nighttime traffic noise levels to be associated with sleep disorders especially among persons with higher scores for trait anxiety (7). The lack of association with hypnotics in the current analyses may be due to lack of power as 
Table 3. Odds ratios (OR) for associations of road traffic noise $\left(\mathrm{L}_{\text {den }}\right)$ with poor self-rated health and psychotropic medication use among men. [95\% $\mathrm{Cl}=95 \%$ confidence interval]

\begin{tabular}{|c|c|c|c|c|c|c|}
\hline \multirow[t]{2}{*}{ Noise level } & \multicolumn{3}{|c|}{ Poor self-rated health } & \multicolumn{3}{|c|}{ Psychotropic medication use } \\
\hline & $\mathrm{N}$ & $\mathrm{OR}$ & $95 \% \mathrm{Cl}$ & $\mathrm{N}$ & OR & $95 \% \mathrm{Cl}$ \\
\hline \multicolumn{7}{|l|}{ Model 1 a } \\
\hline $45.1-50 \mathrm{~dB}$ & 820 & 0.95 & $0.74-1.21$ & 826 & 0.82 & $0.59-1.13$ \\
\hline $50.1-55 \mathrm{~dB}$ & 710 & 1.22 & $0.95-1.56$ & 716 & 1.05 & $0.76-1.45$ \\
\hline $55.1-60 \mathrm{~dB}$ & 461 & 1.17 & $0.89-1.54$ & 461 & 0.81 & $0.55-1.19$ \\
\hline$>60 \mathrm{~dB}$ & 523 & 1.40 & $1.08-1.82$ & 534 & 0.92 & $0.64-1.31$ \\
\hline \multicolumn{7}{|l|}{ Model 2 b } \\
\hline$\leq 45 \mathrm{~dB}$ & 402 & 1.00 & & 402 & 1.00 & \\
\hline $45.1-50 \mathrm{~dB}$ & 614 & 0.95 & $0.69-1.30$ & 615 & 0.90 & $0.60-1.35$ \\
\hline $50.1-55 \mathrm{~dB}$ & 519 & 1.26 & $0.92-1.74$ & 520 & 1.25 & $0.84-1.87$ \\
\hline $55.1-60 \mathrm{~dB}$ & 327 & 1.31 & $0.92-1.87$ & 327 & 0.87 & $0.54-1.41$ \\
\hline$>60 \mathrm{~dB}$ & 389 & 1.58 & $1.14-2.21$ & 391 & 0.79 & $0.50-1.25$ \\
\hline
\end{tabular}

a Unadjusted model.

${ }^{\mathrm{b}}$ Model adjusted for age, occupational status, level of education, size of residence, marital status, job strain, chronic disease, area-level socioeconomic status and population density.

only $5.9 \%$ of men and $7.7 \%$ of women had purchased hypnotics. It is also possible that the subjective health problems, as indicated by poor self-rated health and sleep disturbances (in our previous study), have been mild and below the threshold to seek medical aid [the different noise metrics used in our previous $\left(\mathrm{L}_{\text {night }}\right)$ and this $\left(\mathrm{L}_{\mathrm{den}}\right)$ study were highly correlated with Pearson correlation coefficient 0.99]. Furthermore, we did not have data on traffic noise exposure levels indoors, where people spend most of their time. In Finland, the indoor noise levels are clearly lower than the outdoor levels because of the good residential building structures such as triple glazed-windows (48) (the minimum requirement is double-glazed).

We found a sex-specific association in relation to poor self-rated health. Noise may be differently perceived by sex; however, others have shown that traffic noise annoyance is more commonly reported by women than men (49), and we have shown that the association between night-time traffic noise and sleep problems may be more pronounced among women than men (7). Both of these findings indicate sex differences opposite to those observed in this study. A further potential explanation involves the specific health outcome (selfrated health). Although perceived health is likely to be reported equally reliably by men and women (50), some studies have shown that self-rated health may be a better predictor of severe health outcomes, such as mortality, among men than women $(27,51)$. This is possibly due to a higher threshold for reporting poor health among men than women, and suggests that perceived health may reflect different components of physical and mental health among men and women.

Further analyses revealed that the associations between noise and self-rated health were present only
Table 4. Odds ratios (OR) for associations of road traffic noise $\left(\mathrm{L}_{\text {den }}\right)$ with poor self-rated health and psychotropic medication use among women. [ $95 \% \mathrm{Cl}=95 \%$ confidence interval]

\begin{tabular}{lcccccc}
\hline \multirow{2}{*}{ Noise level } & \multicolumn{3}{c}{ Poor self-rated health } & \multicolumn{4}{c}{ Psychotropic medication use } \\
\cline { 2 - 7 } & $\mathrm{N}$ & OR & $95 \% \mathrm{Cl}$ & $\mathrm{N}$ & OR & $95 \% \mathrm{Cl}$ \\
\hline Model 1 a & & & & & & \\
$\leq 45 \mathrm{~dB}$ & 2255 & 1.00 & & 2272 & 1.00 & \\
$45.1-50 \mathrm{~dB}$ & 3260 & 0.93 & $0.83-1.05$ & 3284 & 0.92 & $0.80-1.06$ \\
$50.1-55 \mathrm{~dB}$ & 2855 & 0.90 & $0.80-1.02$ & 2881 & 0.90 & $0.77-1.04$ \\
$55.1-60 \mathrm{~dB}$ & 1969 & 0.90 & $0.79-1.03$ & 1984 & 0.99 & $0.84-1.15$ \\
$>60 \mathrm{~dB}$ & 2077 & 0.86 & $0.75-0.98$ & 2104 & 1.02 & $0.88-1.19$ \\
Model 2 ${ }^{\mathrm{b}}$ & & & & & & \\
$\leq 45 \mathrm{~dB}$ & 1605 & 1.00 & & 1610 & 1.00 & \\
$45.1-50 \mathrm{~dB}$ & 2392 & 0.96 & $0.83-1.12$ & 2398 & 0.93 & $0.78-1.11$ \\
$50.1-55 \mathrm{~dB}$ & 2051 & 0.88 & $0.75-1.04$ & 2059 & 0.86 & $0.72-1.03$ \\
$55.1-60 \mathrm{~dB}$ & 1398 & 0.89 & $0.75-1.06$ & 1404 & 1.00 & $0.82-1.21$ \\
$>60 \mathrm{~dB}$ & 1469 & 0.91 & $0.77-1.08$ & 1478 & 0.96 & $0.80-1.17$ \\
\hline a Unadjusted model \\
b Model adjusted for age, occupational status, level of education, size of \\
residence, marital status, job strain, chronic disease, area-level socio- \\
economic status and population density.
\end{tabular}

among men who reported higher trait anxiety scores. In a large number of studies road traffic noise has been related to annoyance $(10,11)$. Annoyance ratings to traffic noise have further been linked to trait anxiety (52), and thus, personality disposition, such as trait anxiety, may act as a moderating factor in the health effects of noise. We have previously reported night-time traffic noise to be associated with sleep disorders more strongly among those with trait anxiety (7). This suggests that anxiety does not increase the effect of noise on health only through conscious mental processes such as annoyance. Further research is needed to recognize other personal characteristics that may increase the individual's vulnerability to the effects of road traffic noise.

The following limitations should be considered when interpreting these findings. First, we had limited data on area-level confounders. Therefore, we could not evaluate to what extent traffic noise acts as an indicator rather than a causal factor for poor environment (eg, lack of green space, poor air quality, and unsafe neighborhood). Although most requirements for the modeling of road traffic noise were the same in the three cities, some differences in the modeling existed. However, noise modeling always includes some uncertainty and it is likely that these differences had only a minor effect on the study results. Some imprecision in the current noise modeling is due to the lack of information about traffic intensities on small streets. As the data were cross-sectional, interpretations of the causality of the associations cannot be made. Further, as most participants supposedly spend on average 8-9 hours on a week day at work and commuting, noise exposures away from home may have affected the results. However, high noise exposure at work, for example, could have biased the observed associations only if high occupational exposure would 
Table 5. Odds ratios (OR) for associations for road traffic noise $\left(L_{\text {den }}\right)$ with poor self-rated health among men by trait anxiety score. $[95 \% \mathrm{Cl}=95 \%$ confidence interval]

\begin{tabular}{lccc}
\hline Noise level $\left(\mathrm{L}_{\text {den }}\right)$ & \multicolumn{3}{c}{ Poor self-rated health } \\
\cline { 2 - 4 } & $\mathrm{N}$ & OR & $95 \% \mathrm{Cl}$ \\
\hline High anxiety a & 122 & 1.00 & \\
$\leq 45 \mathrm{~dB}$ & 211 & 1.05 & $0.63-1.74$ \\
$45.1-50 \mathrm{~dB}$ & 169 & 1.59 & $0.95-2.57$ \\
$50.1-55 \mathrm{~dB}$ & 113 & 1.23 & $0.70-2.18$ \\
$55.1-60 \mathrm{~dB}$ & 132 & 2.23 & $1.28-3.89$ \\
$>60 \mathrm{~dB}$ & & & \\
Low anxiety a & 270 & 1.00 & \\
$\leq 45 \mathrm{~dB}$ & 395 & 0.70 & $0.45-1.11$ \\
$45.1-50 \mathrm{~dB}$ & 346 & 1.00 & $0.64-1.55$ \\
$50.1-55 \mathrm{~dB}$ & 207 & 1.33 & $0.82-2.16$ \\
$55.1-60 \mathrm{~dB}$ & 242 & 1.20 & $0.75-1.92$ \\
$>60 \mathrm{~dB}$ & &
\end{tabular}

a Model adjusted for age, occupational status, level of education, size of residence, marital status, job strain, chronic disease, area-level socioeconomic status and population density.

have been associated with high noise exposure at home. The generalizability of these findings to other countries may also be limited because of the building characteristics, which leads to different indoor noise levels. Due to harsh climate in Finland minimum of double windows are required for all residential buildings, for example, and keeping windows open is less frequent especially during the cold season (53).

Despite these limitations, our study, where the participants were blind to the aim of the study at the time of the surveys, provides important population-level evidence to suggest that traffic noise levels $>60 \mathrm{~dB}$ are associated with poor self-rated health among employed men, particularly those with higher trait anxiety scores. However, the perceived decline in health status did not lead to increased use of medication, indicated by the absence of associations between traffic noise and psychotropic medication use. Future research should evaluate the biological and psychological mechanisms linking traffic noise exposure with weakened self-rated health and the further medical consequences of the effect.

\section{Acknowledgment}

The cities of Helsinki, Vantaa and Turku are acknowledged for providing the noise data. This study was supported by the EU ERA-AGE2 program funded by the Academy of Finland (project 264944) and the Ministry of Social Affairs and Health. Mika Kivimäki is supported by the Medical Research Council (K013351), the Finnish Work Environment Fund and a professorial fellowship from the UK Economic and Social Research Council. The funders had no role in study design; the collection, analysis and interpretation of data; the writing of the report; or the decision to submit the article for publication.

\section{References}

1. WHO. Guidelines for Community Noise. Geneva: World Health Organization; 1999 [cited April 3, 2013]. Available from: http://www.who.int/docstore/peh/noise/guidelines2. html.

2. WHO. Night Noise Guidelines for Europe. Copenhagen: WHO Regional Office for Europe; 2009.

3. European Comission. The Environmental Noise Directive (2002/49/EC); 2002 [cited April 4, 2013]. Available from: http://ec.europa.eu/environment/noise/directive.htm.

4. Ministry of the Environment of Finland. Liikenteen ympärisöhaitat [Environmental harms of traffic]. 2011 [updated February 17,2011 Accessed Dec 18,2012]; Available from: http:// www.ymparisto.fi/default.asp?contentid=377006\&lan=FI.

5. WHO. Burden of disease from environmental noise. Quantification of healthy life years lost in Europe. Bonn, Germany; 2011.

6. Tetreault LF, Perron S, Smargiassi A. Cardiovascular health, traffic-related air pollution and noise: are associations mutually confounded? A systematic review. Int J Public Health. 2013;58(5):649-66. http://dx.doi.org/10.1007/s00038-0130489-7.

7. Halonen JI, Vahtera J, Stansfeld S, Yli-Tuomi T, Salo P, Pentti J, et al. Associations between Nocturnal Traffic Noise and Sleep: the Finnish Public Sector Study. Environ Health Perspect. 2012;120(10):1391-6. http://dx.doi.org/10.1289/ ehp. 1205026 .

8. Brink M. Parameters of well-being and subjective health and their relationship with residential traffic noise exposure - A representative evaluation in Switzerland. Environ Int. 2011 May;37(4):723-33. http://dx.doi.org/10.1016/j. envint.2011.02.011.

9. Pirrera S, De Valck E, Cluydts R. Nocturnal road traffic noise: A review on its assessment and consequences on sleep and health. Environ Int. 2010 Jul;36(5):492-8. http://dx.doi. org/10.1016/j.envint.2010.03.007.

10. Kim M, Chang SI, Seong JC, Holt JB, Park TH, Ko JH, et al. Road traffic noise: annoyance, sleep disturbance, and public health implications. Am J Prev Med. 2012;43(4):353-60. http:// dx.doi.org/10.1016/j.amepre.2012.06.014.

11. Bjork J, Ardo J, Stroh E, Lovkvist H, Ostergren PO, Albin M. Road traffic noise in southern Sweden and its relation to annoyance, disturbance of daily activities and health. Scand J Work Environ Health. 2006 Oct;32(5):392-401. http://dx.doi. org/10.5271/sjweh.1035.

12. Parra DC, Gomez LF, Sarmiento OL, Buchner D, Brownson R, Schimd T, et al. Perceived and objective neighborhood environment attributes and health related quality of life among the elderly in Bogota, Colombia. Soc 
Sci Med. 2010;70(7):1070-6. http://dx.doi.org/10.1016/j. socscimed.2009.12.024.

13. Hardoy MC, Carta MG, Marci AR, Carbone F, Cadeddu M, Kovess V, et al. Exposure to aircraft noise and risk of psychiatric disorders: the Elmas survey--aircraft noise and psychiatric disorders. Soc Psychiatry Psychiatr Epidemiol. 2005;40(1):24-6. http://dx.doi.org/10.1007/s00127-0050837-x.

14. Franssen EA, van Wiechen CM, Nagelkerke NJ, Lebret E. Aircraft noise around a large international airport and its impact on general health and medication use. Occup Environ Med. 2004;61(5):405-13. http://dx.doi.org/10.1136/ oem.2002.005488

15. Stansfeld SA, Berglund B, Clark C, Lopez-Barrio I, Fischer $\mathrm{P}$, Ohrstrom E, et al. Aircraft and road traffic noise and children's cognition and health: a cross-national study. Lancet. 2005;365(9475):1942-9. http://dx.doi.org/10.1016/S01406736(05)66660-3.

16. Clark C, Crombie R, Head J, van Kamp I, van Kempen E, Stansfeld SA. Does traffic-related air pollution explain associations of aircraft and road traffic noise exposure on children's health and cognition? A secondary analysis of the United Kingdom sample from the RANCH project. Am J Epidemiol. 2012;176(4):327-37. http://dx.doi.org/10.1093/ aje/kws012.

17. Floud S, Vigna-Taglianti F, Hansell A, Blangiardo M, Houthuijs $\mathrm{D}$, Breugelmans $\mathrm{O}$, et al. Medication use in relation to noise from aircraft and road traffic in six European countries: results of the HYENA study. Occup Environ Med. 2011;68(7):518 24. http://dx.doi.org/10.1136/oem.2010.058586.

18. Bocquier A, Cortaredona S, Boutin C, David A, Bigot A, Sciortino $\mathrm{V}$, et al. Is exposure to night-time traffic noise a risk factor for purchase of anxiolytic-hypnotic medication? A cohort study. Eur J Public Health. 2013. [Epub ahead of print]. http://dx.doi.org/10.1093/eurpub/ckt117.

19. de Kluizenaar Y, Janssen SA, van Lenthe FJ, Miedema HM, Mackenbach JP. Long-term road traffic noise exposure is associated with an increase in morning tiredness. J Acoust Soc Am. 2009 Aug;126(2):626-33. http://dx.doi. org/10.1121/1.3158834

20. Fyhri A, Klaeboe R. Road traffic noise, sensitivity, annoyance and self-reported health--a structural equation model exercise. Environ Int. 2009;35(1):91-7. http://dx.doi.org/10.1016/j. envint.2008.08.006

21. Pöyry Finland Ltd. Ympäristömeludirektiivin mukainen ympäristömeluselvitys Turussa [Noise report based on parameters according to European Community environmental directives in the Turku city area. Helsinki; 2012.

22. Lahti T, Gouatarbès B, Markula T. [Helsingin kaupungin meluselvitys 2007] City of Helsinki: strategic noise mapping 2007 (summary in English). Helsinki: City of Helsinki; 2007.

23. Ramboll Finland Ltd. Vantaan yleiskaavan meluselvitys [Strategic noise mapping for the zoning plan of the city of Vantaa]. City of Vantaa, Kuntatekniikan keskus; 2007.

24. Bendtsen $\mathrm{H}$. The Nordic prediction method for road traffic noise. The Science of the Total Environment. 1999;235:331-8. http://dx.doi.org/10.1016/S0048-9697(99)00216-8.

25. Jurges H, Avendano M, Mackenbach JP. Are different measures of self-rated health comparable? An assessment in five European countries. Eur J Epidemiol. 2008;23(12):77381. http://dx.doi.org/10.1007/s10654-008-9287-6.

26. Krause NM, Jay GM. What do global self-rated health items measure? Med Care. 1994;32(9):930-42. http://dx.doi. org/10.1097/00005650-199409000-00004.

27. Idler EL, Russell LB, Davis D. Survival, functional limitations, and self-rated health in the NHANES I Epidemiologic Follow-up Study, 1992. First National Health and Nutrition Examination Survey. Am J Epidemiol. 2000;152(9):874-83. http://dx.doi.org/10.1093/aje/152.9.874.

28. Klaukka T. The Finnish database on drug utilisation. Nor J Epidemiology. 2001;11(1):19-22.

29. WHO Collaborating Centre for Drug Statistics Methodology. Guidelines for ATC classification and DDD assignment 2012. Oslo; 2011

30. Kivimaki M, Honkonen T, Wahlbeck K, Elovainio M, Pentti J, Klaukka T, et al. Organisational downsizing and increased use of psychotropic drugs among employees who remain in employment. J Epidemiol Community Health. 2007;61(2):154 8. http://dx.doi.org/10.1136/jech.2006.050955.

31. van Kamp I, Davies H. Environmental noise and mental health: Five year review and future directions 9 th International Congress on Noise as a Public Health Problem (ICBEN) 2008. Foxwoods, CT, USA; 2008.

32. Marteau TM, Bekker H. The development of a six-item shortform of the state scale of the Spielberger State-Trait Anxiety Inventory (STAI). Br J Clin Psychol. 1992;31:301-6. http:// dx.doi.org/10.1111/j.2044-8260.1992.tb00997.x.

33. Statistics Finland. Classification of Occupations. Helsinki: Statistics Finland; 1987.

34. Kivimaki M, Nyberg ST, Batty GD, Fransson EI, Heikkila $\mathrm{K}$, Alfredsson $\mathrm{L}$, et al. Job strain as a risk factor for coronary heart disease: a collaborative meta-analysis of individual participant data. Lancet. 2012;380(9852):1491-7. http:// dx.doi.org/10.1016/S0140-6736(12)60994-5.

35. Ainsworth BE, Haskell WL, Whitt MC, Irwin ML, Swartz AM, Strath SJ, et al. Compendium of physical activities: an update of activity codes and MET intensities. Med Sci Sports Exerc. 2000 Sep;32(9 Suppl):S498-504. http://dx.doi. org/10.1097/00005768-200009001-00009.

36. Halonen JI, Kivimaki M, Virtanen M, Pentti J, Subramanian SV, Kawachi I, et al. Living in proximity of a bar and risky alcohol behaviours: a longitudinal study. Addiction. 2013;108(2):320-8. http://dx.doi.org/10.1111/j.13600443.2012.04053.x.

37. KELA (Social Insurance Institute of Finland). Medicine Reimbursement Statistics [cited 2012 Sept 20]. Available from: http://www.kela.fi/in/internet/english.nsf/NET/2207031259 09MP?OpenDocument.

38. Teppo L, Pukkala E, Lehtonen M. Data quality and quality control of a population-based cancer registry. Experience 
in Finland. Acta Oncol. 1994;33(4):365-9. http://dx.doi. org/10.3109/02841869409098430.

39. Havard S, Reich BJ, Bean K, Chaix B. Social inequalities in residential exposure to road traffic noise: an environmental justice analysis based on the RECORD Cohort Study. Occup Environ Med. 2011 May;68(5):366-74. http://dx.doi. org/10.1136/oem.2010.060640.

40. Gary-Webb TL, Baptiste-Roberts K, Pham L, Wesche-Thobaben J, Patricio J, Pi-Sunyer FX, et al. Neighborhood socioeconomic status, depression, and health status in the Look AHEAD (Action for Health in Diabetes) study. BMC Public Health. 2011;11:349. http://dx.doi.org/10.1186/1471-2458-11-349.

41. Statistics Finland. Grid Database 2007 [cited April 3, 2013]. Available from: http://www.tilastokeskus.fi/tup/ ruututietokanta/index_en.html.

42. Halonen JI, Kivimaki M, Pentti J, Kawachi I, Virtanen M, Martikainen P, et al. Quantifying neighbourhood socioeconomic effects in clustering of behaviour-related risk factors: a multilevel analysis. PLoS One. 2012;7(3):e32937. http://dx.doi.org/10.1371/journal.pone.0032937.

43. Tarnopolsky A, Watkins G, Hand DJ. Aircraft noise and mental health: I. Prevalence of individual symptoms. Psychol Med. 1980;10(4):683-98. http://dx.doi.org/10.1017/ S0033291700054982.

44. Svedberg P, Bardage C, Sandin S, Pedersen NL. A prospective study of health, life-style and psychosocial predictors of selfrated health. Eur J Epidemiol. 2006;21(10):767-76. http:// dx.doi.org/10.1007/s10654-006-9064-3.

45. Molarius A, Berglund K, Eriksson C, Lambe M, Nordstrom E, Eriksson HG, et al. Socioeconomic conditions, lifestyle factors, and self-rated health among men and women in Sweden. Eur J Public Health. 2007;17(2):125-33. http:// dx.doi.org/10.1093/eurpub/ck1070.

46. Selander J, Bluhm G, Theorell T, Pershagen G, Babisch W, Seiffert I, et al. Saliva cortisol and exposure to aircraft noise in six European countries. Environ Health Perspect. 2009;117(11):1713-7.
47. Sorensen M, Hvidberg M, Hoffmann B, Andersen ZJ, Nordsborg RB, Lillelund KG, et al. Exposure to road traffic and railway noise and associations with blood pressure and self-reported hypertension: a cohort study. Environ Health. 2011;10(92):92. http://dx.doi.org/10.1186/1476069X-10-92.

48. Garg N, Sharma O, Maji S. Experimental investigations on sound insulation through single, double \& triple window glazing for traffic noise abatement. J Sci Ind Res. 2011;70(6):471-8.

49. Dratva J, Zemp E, Felber Dietrich D, Bridevaux PO, Rochat $T$, Schindler $C$, et al. Impact of road traffic noise annoyance on health-related quality of life: results from a population-based study. Qual Life Res. 2010;19(1):37-46. http://dx.doi.org/10.1007/s11136-009-9571-2.

50. Martikainen P, Aromaa A, Heliovaara M, Klaukka T, Knekt P, Maatela J, et al. Reliability of perceived health by sex and age. Soc Sci Med. 1999;48(8):1117-22. http://dx.doi.org/10.1016/ S0277-9536(98)00416-X.

51. Jylha M, Guralnik JM, Ferrucci L, Jokela J, Heikkinen E. Is self-rated health comparable across cultures and genders? J Gerontol B Psychol Sci Soc Sci. 1998;53(3):S144-52. http:// dx.doi.org/10.1093/geronb/53B.3.S144.

52. Persson R, Bjork J, Ardo J, Albin M, Jakobsson K. Trait anxiety and modeled exposure as determinants of self-reported annoyance to sound, air pollution and other environmental factors in the home. Int Arch Occup Environ Health. 2007;81(2):179-91. http://dx.doi.org/10.1007/s00420-0070204-1.

53. Lanki T, Ahokas A, Alm S, Janssen NA, Hoek G, De Hartog JJ, et al. Determinants of personal and indoor PM2.5 and absorbance among elderly subjects with coronary heart disease. J Expo Sci Environ Epidemiol. 2007 Mar;17(2):124 33. http://dx.doi.org/10.1038/sj.jes.7500470.

Received for publication: 20 September 2013 